\title{
Elderly Patients With Squamous Cell Carcinoma of the Head and Neck and the Benefit of Multimodality Therapy
}

\author{
Virginia A. Moye, ${ }^{b}$ Sindhu Chandramouleeswaran, ${ }^{b}$ Ni Zhao, ${ }^{a}$ Hyman B. Muss, ${ }^{b}$ Mark C. Weissler, ${ }^{c}$ David N. Hayes, ${ }^{b}$ \\ Jose P. ZEVALLOS ${ }^{c}$

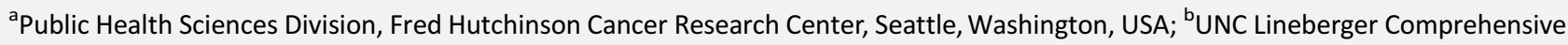 \\ Cancer Center and ' Department of Otolaryngology/Head and Neck Surgery, University of North Carolina at Chapel Hill, Chapel Hill, \\ North Carolina, USA \\ Disclosures of potential conflicts of interest may be found at the end of this article.
}

Key Words. Head and neck neoplasms - Aged - Drug therapy • Surgical therapy - Radiotherapy

\section{ABSTRACT}

Background. Limited data are available regarding outcomes in elderly head and neck cancer patients. This retrospective study was designed to characterize head and neck cancer in geriatric patients.

Patients and Methods. This study included all patients in a large university-based tumor registry who were diagnosed with head and neck cancer from January 1, 1990, to December 31, 2005. Patients aged $\geq 70$ years at the time of diagnosis were defined as older. Overall survival and progression-free survival were censored at 60 months. Survival differences were compared using the log-rank test. Hazard ratios were estimated using a Cox proportional hazards model, adjusting for potential confounders.

Results. Of 1,598 patients identified, 1,166 patients were aged $<70$ years (i.e., younger) and 281 patients were aged $\geq 70$ years (older). When controlling for possible confounders, older patients were nearly twice as likely to die within 5 years as their younger counterparts (hazard ratio: 1.92). The median life expectancy for older patients was nearly 5 years for stage I-II disease and $<2$ years for stage III-IV disease. Older patients with stage III-IV disease who received multimodality therapy had 5-year survival similar to that younger patients with stage III-IV disease who were treated similarly (33.2\% vs. 44.0\%). Older patients with stage III-IV disease who received single-modality therapy had extremely poor survival compared with all other patients (hazard ratio for progressionfree survival: 1.5).

Conclusion. This study highlights the need for better understanding of the factors affecting head and neck cancer outcomes in elderly patients. Information about life expectancy in elderly head and neck cancer patients may help guide treatment decisions. The Oncologist 2015;20:159-165

Implications for Practice: In this study we demonstrate that elderly patients with early stage head and neck cancer did just as well as younger patients in terms of cancer outcomes but had increased mortality from other causes. In patients at advanced stage, those treated in a stage-appropriate manner with multimodality therapy had overall survival similar to that of younger patients. This study demonstrated age as an independent predictor of survival in head and neck cancer. It also highlighted the need for better understanding of factors that preclude the delivery of stage-appropriate care in elderly patients with head and neck cancer.

\section{INTRODUCTION}

Cancers of the head and neck are the fifth most common cancer worldwide and responsible for more than 200,000 deaths per year [1]. More than $50 \%$ of head and neck cancer cases occur in patients aged $\geq 60$ years, and $28 \%$ occur in patients aged $\geq 70$ years. With an aging population, we will likely face increasing numbers of elderly head and neck cancer patients in the coming years. Despite this, few studies have focused specifically on the characteristics and treatment of older patients with squamous cell carcinoma of the head and neck (HNSCC). Of those studies that exist, several have shown that elderly patients can achieve outcomes similar to those of younger patients if treated with similar therapies [2-9]. Others have noted worse outcomes in older patients but have concluded that the higher risk of mortality is entirely due to higher comorbidity status and competing causes of mortality rather than chronological age $[10,11]$, whereas others have suggested that age is an independent prognostic variable $[11,12]$. Multiple studies have also concluded that geriatric

Correspondence: David N. Hayes, M.D., M.P.H., UNC Lineberger Comprehensive Cancer Center, School of Medicine CB\#7295, University of North Carolina at Chapel Hill, 450 West Drive, Chapel Hill, North Carolina 27599-7295, USA. Telephone: 919-966-3786; E-Mail: hayes@med.unc. edu Received August 18, 2014; accepted for publication December 3, 2014; first published online in The Oncologist Express on January $12,2015$. CAlphaMed Press 1083-7159/2015/\$20.00/0 http://dx.doi.org/10.1634/theoncologist.2013-0325 
patients with head and neck cancer frequently receive nonstandard and less aggressive therapies than their younger counterparts [13-15]. Receiving nonstandard therapy is an independent risk factor for decreased survival $[16,17]$.

Despite the encouragingly similar outcomes and rates of adverse treatment effects between elderly and younger patients in some studies [18-20], other investigators identified higher rates of complications in older patients [21, 22]. In addition, cancer clinical trials regularly underrepresent older patients [23-25], and little progress has been made to expand enrollment of the elderly into trials over the past 10 years $[26,27]$. As long as there is a paucity of clinical trial data available to determine standard management for elderly patients, many may continue to receive nonstandard or suboptimal treatment.

Physicians treating elderly patients with HNSCC are faced with a lack of data regarding what constitutes an "elderly" patient and whether to seek curative treatment, considering patient age. More studies are needed to assess real-world outcomes of older patients with HNSCC to provide improved guidance for physicians and patients regarding when and how to treat. The purpose of this retrospective analysis is to more clearly characterize how outcomes in head and neck cancer compare between a large group of older patients and their younger counterparts.

\section{MeTHODS}

\section{Data Source}

Study-related retrospective data were obtained from the University of North Carolina (UNC) Cancer Registry, which contains information regarding all patients who are diagnosed with cancer and/or receive cancer-directed therapy at UNC hospitals. The registry includes information on demographics, primary tumor site, presence of multiple primary tumors, tumor morphology, stage at diagnosis, treatment, relapse, mortality, and date of last contact. Once enrolled in the registry, all patients are contacted yearly for the remainder of their lives. Losses to follow-up are queried against death records including the Social Security Death Index and other sources.

\section{Study Population}

Study patients included all patients in the UNC Cancer Registry diagnosed between January 1, 1990, and December 31, 2005, with head and neck cancer. This study was approved by the institutional review board (IRB) of the University of North Carolina (IRB number 10-0952). Patients were grouped according to site. Site groups considered included larynx, oropharynx (including tonsil, base of tongue, soft palate), oral cavity (including floor of mouth, buccal mucosa, hard palate, gum, lip, and anterior two-thirds of tongue), and hypopharynx (including pyriform sinus).

Patients were also grouped according to treatment category. Treatment categories considered were surgery only, chemotherapy only, radiation only, surgery then radiation, radiation then surgery, surgery followed by chemotherapy and radiation, chemoradiation, chemoradiation with salvage surgery, no treatment/ palliative care only/hospice, and other (including patients who received no treatment and those for whom treatment modalities or intent of treatment was unknown). Tumor registry data were supplemented with chart review in cases for which treatment categories were ambiguously coded in the tumor registry. To further simplify analysis, surgery then radiation and radiation then surgery were condensed into surgery and radiation. Chemoradiation with salvage surgery and surgery then chemoradiation were placed into the other category because of the small numbers of patients in those categories.

Patients with American Joint Committee on Cancer (AJCC) version 7 stage IVC cancer, including all patients with distant metastasis, were excluded from analysis to focus on outcomes in patients with local-regional tumors typically treated with curative intent (stages I-IVB). Patients whose stage information was not available in the database were excluded. Histologic tumor types excluded to avoid confounding the results include benign tumors, carcinoma in situ, salivary gland tumors, sarcomas, teratomas, Kaposi sarcoma, and lymphomas.

From all data fields in the registry, the following items were evaluated in the current analysis because of known or suspected association with HNSCC outcomes: age, sex, race, smoking status, alcohol use, site group, histologic type, stage at diagnosis, treatment category, relapse, and mortality. For age, patients were divided into 2 groups: $\geq 70$ years (older) and $<70$ years (younger). Recurrence times were calculated from the date of initial diagnosis to the date of recurrence recorded in the database. Patients lost to follow-up were censored at the date of last information entry into the database, whether that was the last date of phone contact or last visit.

In addition to the review of cancer registry data, a selective chart review was conducted that focused on elderly patients with advanced larynx cancer receiving unimodality therapy. The intent of this secondary review was to determine factors that may have precluded this group from receiving multimodality, stage-appropriate therapy. Patient comorbidity data were collected. The initial treatment recommendation, the actual treatment received, and treatment mortality were assessed.

\section{Statistical Analysis}

All statistical analysis was performed using $\mathrm{R}$ version 2.13.1 software (http://cran.r-project.org). Baseline characteristics of patients from each group (younger and older) were compared using a chi-square test for categorical variables and one-way analysis of variance for continuous variables between younger and older patients. Overall survival (OS) was calculated from the date of diagnosis to time of death or date of last follow-up. Progression-free survival (PFS) was calculated from the date of diagnosis to time of first recurrence or death. Both OS and PFS were censored at 60 months. A log-rank test was used to compare survival differences in different age groups. A Cox proportional hazards model was used to estimate the hazard ratio (HR). Factors adjusted for in the multivariate analysis included age, sex, race, smoking status, alcohol use, stage, site, and treatment. These include known risk factors for head and neck cancer $[9,28,29]$ and those variables that differed by age group on univariate analysis. All tests were two-sided with a significance cutoff of .05 .

\section{RESULTS}

\section{Demographics}

A total of 1,447 HNSCC patients (1,166 younger patients, 281 older patients) were identified for inclusion in this study. 
Table 1. Characteristics of younger (aged $<70$ years) and older (aged $\geq 70$ years) patients

\begin{tabular}{|c|c|c|}
\hline $\begin{array}{l}\text { Patient } \\
\text { characteristics }\end{array}$ & $\begin{array}{l}\text { Aged }<70 \text { years } \\
(n=1,166), n(\%)\end{array}$ & $\begin{array}{l}\text { Aged } \geq 70 \text { years } \\
(n=281), n(\%)\end{array}$ \\
\hline \multicolumn{3}{|l|}{ Sex } \\
\hline Female & $268(23)$ & $106(38)^{a}$ \\
\hline Male & $898(77)$ & $175(62)$ \\
\hline \multicolumn{3}{|l|}{ Race } \\
\hline White & $707(61)$ & $229(81)^{a}$ \\
\hline Black & $426(36)$ & 47 (17) \\
\hline Other & $33(3)$ & $5(2)$ \\
\hline \multicolumn{3}{|l|}{ Smoking status } \\
\hline Current & $535(46)$ & $75(27)^{a}$ \\
\hline Previous & $185(16)$ & $73(26)$ \\
\hline Never & $73(6)$ & $26(9)$ \\
\hline Unknown & $373(32)$ & $107(38)$ \\
\hline \multicolumn{3}{|l|}{ Alcohol use } \\
\hline Current & $378(32)$ & $68(24)^{a}$ \\
\hline Past & $215(18)$ & $34(13)$ \\
\hline Never & $178(16)$ & $71(25)$ \\
\hline Unknown & $395(34)$ & $108(38)$ \\
\hline \multicolumn{3}{|l|}{ Stage } \\
\hline I & $174(15)$ & $69(25)^{a}$ \\
\hline II & $173(15)$ & 55 (19) \\
\hline III & $189(16)$ & 47 (17) \\
\hline IV & $630(54)$ & 110 (39) \\
\hline \multicolumn{3}{|l|}{ Site } \\
\hline Hypopharynx & $110(9)$ & $26(9)^{a}$ \\
\hline Larynx & $356(31)$ & $86(30)$ \\
\hline Oral cavity & $219(19)$ & $89(32)$ \\
\hline Oropharynx & $422(36)$ & $61(22)$ \\
\hline Other & $59(5)$ & $19(7)$ \\
\hline \multicolumn{3}{|l|}{ Treatment } \\
\hline Surgery only & $147(13)$ & $35(12)^{a}$ \\
\hline Radiation only & $175(15)$ & $61(22)$ \\
\hline $\begin{array}{l}\text { Chemotherapy plus } \\
\text { radiation }\end{array}$ & $271(23)$ & $26(9)$ \\
\hline $\begin{array}{l}\text { Surgery plus } \\
\text { radiation }\end{array}$ & $380(32)$ & 104 (37) \\
\hline Chemotherapy only & $30(3)$ & $1(0)$ \\
\hline Other & $163(14)$ & 54 (19) \\
\hline
\end{tabular}

${ }^{\mathrm{a}} p<.01$.

Comprehensive demographic information is shown in Table 1. The median age for the older group was 75 years. Patients in this group were more likely to be female, white, diagnosed with lower stage cancer, previous smokers, and never drinkers. Siterelated categorization indicates that older patients were much more likely to have oral cavity cancer ( $32 \%$ vs. $19 \%, p<.01)$ and less likely to have oropharyngeal cancer ( $22 \%$ vs. $36 \%, p<.01)$. Combined surgery and radiation therapy was the most frequent treatment among both age categories. In addition, younger patients were more likely than older patients to receive chemotherapy and radiation together.

\section{Univariate Survival Analysis}

In the univariate analysis, age $\geq 70$ years was significantly associated with an increased risk of death (HR: 1.51; 95\% confidence interval [Cl]: 1.29-1.78) (Table 2). In addition to age, the univariate analysis confirmed prior reports of unfavorable outcomes including worse OS and PFS associated with nonwhite race, male sex, any history of alcohol use, any history of smoking, having cancer of the hypopharynx, and having higher stage cancer (Table 2). A small number of patients included in the study $(<2 \%)$ were treated with palliative intent (chemotherapy only) despite having AJCC staging that would generally be treated for cure. Such patients generally had unusual circumstances or comorbidities and experienced statistically significantly worse outcomes (HR for OS: 3.15 ; $95 \% \mathrm{Cl}: 1.85-5.36)$.

\section{Multivariate Survival Analysis}

To adjust for confounding effects of known risk factors on the impact of age, multivariate analysis was performed (Table 2). After controlling for other factors, the negative impact of age on outcomes was increased. Review of the data reveals that increasing age is associated with earlier stage tumors, especially in oral cavity cancers. Accordingly, controlling for stage unmasked even more risk associated with advanced age. When controlling for confounders, older patients were nearly twice as likely to die (HR: $1.92 ; 95 \% \mathrm{Cl}: 1.62-2.28 ; p<.0001$ ) and $70 \%$ more likely to die or relapse compared with their younger counterparts (HR: $1.68 ; 95 \% \mathrm{Cl}: 1.43-1.97 ; p<.0001$ ). In the multivariate analysis, many covariates remained statistically significant, including race, smoking status, tumor stage, tumor site, and treatment modality. As expected, increased risk associated with multimodality therapy seen in the univariate analysis disappears after controlling for stage. Patients receiving radiation therapy alone continued to have considerably poorer outcomes compared with patients receiving surgery alone. This may be explained by treatment bias directing patients unfit for surgery, and presumably sicker overall, to radiation only.

\section{Subgroup Analysis}

The finding of worse outcomes in older patients in the univariate analysis was expected from prior literature. Based on Kaplan-Meier modeling, patients aged $\geq 70$ years at diagnosis had median OS of 35 months $(95 \% \mathrm{Cl}$ : $28-41$ months), whereas younger patients had median OS of 60 months (95\% Cl: 55-68 months; $p<.0001)$. Older patients had shorter median PFS at 25 months ( $95 \% \mathrm{Cl}$ : 20-32 months) in comparison with the younger cohort, with median PFS of 44 months (95\% Cl: 38-52 months; $p<.0001$ ). The median life expectancy for elderly patients with early stage cancer was nearly 5 years ( 56 months: $95 \% \mathrm{Cl}$ : 38-71 months). The HR for death or relapse in the older cohort was $51 \%$ higher than in younger patients. Consequently, we turned our attention to possible interactions between age, stage, intensity of treatment, and adverse outcomes to better understand this unexpected finding.

We considered whether poorer outcomes in older patients might be related to physicians systematically offering less intensive therapy. In this analysis, therapy was simplified to unimodality (surgery or radiation alone) or multimodality 
Table 2. Analysis of overall and progression free survival hazard ratios

\begin{tabular}{|c|c|c|c|c|}
\hline \multirow[b]{2}{*}{ Patient characteristics } & \multicolumn{2}{|c|}{ Univariate analysis } & \multicolumn{2}{|c|}{ Multivariate analysis $^{a}$} \\
\hline & OS, HR (95\% Cl) & PFS, HR (95\% CI) & OS, HR (95\% Cl) & PFS, HR (95\% Cl) \\
\hline \multicolumn{5}{|l|}{ Age } \\
\hline$<70$ years & 1 (reference) & 1 (reference) & 1 (reference) & 1 (reference) \\
\hline$\geq 70$ years & $1.512(1.29-1.78)^{d}$ & $1.44(1.23-1.68)^{d}$ & $1.92(1.62-2.28)^{d}$ & $1.68(1.43-1.97)^{d}$ \\
\hline \multicolumn{5}{|l|}{ Sex } \\
\hline Female & 1 (reference) & 1 (reference) & 1 (reference) & 1 (reference) \\
\hline Male & $1.22(1.04-1.43)^{\mathrm{b}}$ & $1.14(0.98-1.32)$ & $1.10(0.93-1.30)$ & $1.07(0.92-1.25)$ \\
\hline \multicolumn{5}{|l|}{ Race } \\
\hline White & 1 (reference) & 1 (reference) & 1 (reference) & 1 (reference) \\
\hline Black & $1.357(1.18-1.57)^{d}$ & $1.21(1.05-1.39)^{c}$ & $1.26(1.09-1.47)^{c}$ & $1.14(0.99-1.31)$ \\
\hline Other & $1.44(0.96-2.15)$ & $1.39(0.95-2.05)$ & $1.76(1.17-2.65)^{c}$ & $1.65(1.11-2.43)^{\mathrm{b}}$ \\
\hline \multicolumn{5}{|l|}{ Smoking status } \\
\hline Never & 1 (reference) & 1 (reference) & 1 (reference) & 1 (reference) \\
\hline Other & $2.20(1.58-3.08)^{d}$ & $1.76(1.33-2.34)^{d}$ & $1.81(1.27-2.57)^{\mathrm{C}}$ & $1.54(1.13-2.08)^{c}$ \\
\hline \multicolumn{5}{|l|}{ Alcohol use } \\
\hline Never & 1 (reference) & 1 (reference) & 1 (reference) & 1 (reference) \\
\hline Other & $1.43(1.18-1.74)^{d}$ & $1.25(1.05-1.49)^{\mathrm{b}}$ & $1.16(0.94-1.43)$ & $1.08(0.89-1.31)$ \\
\hline \multicolumn{5}{|l|}{ Stage } \\
\hline Early (I and II) & 1 (reference) & 1 (reference) & 1 (reference) & 1 (reference) \\
\hline Late (III and IVA-B) & $2.08(1.78-2.45)^{d}$ & $1.68(1.46-1.95)^{d}$ & $2.08(1.75-2.47)^{d}$ & $1.77(1.52-2.08)^{\mathrm{d}}$ \\
\hline \multicolumn{5}{|l|}{ Site } \\
\hline Hypopharynx & 1 (reference) & 1 (reference) & 1 (reference) & 1 (reference) \\
\hline Oropharynx & $0.62(0.50-0.78)^{d}$ & $0.68(0.54-0.84)^{d}$ & $0.74(0.59-0.93)^{b}$ & $0.77(0.61-0.96)^{\mathrm{b}}$ \\
\hline Other & $0.48(0.38-0.59)^{d}$ & $0.60(0.48-0.74)^{d}$ & $0.61(0.49-0.76)^{d}$ & $0.72(0.58-0.90)^{\mathrm{c}}$ \\
\hline \multicolumn{5}{|l|}{ Treatment } \\
\hline Surgery only & 1 (reference) & 1 (reference) & 1 (reference) & 1 (reference) \\
\hline Radiation only & $1.69(1.30-2.20)^{\mathrm{d}}$ & $1.65(1.29-2.09)^{d}$ & $1.48(1.13-1.95)^{c}$ & $1.52(1.19-1.96)^{d}$ \\
\hline Chemotherapy plus radiation & $1.62(1.27-2.07)^{d}$ & $1.38(1.10-1.73)^{c}$ & $1.08(0.83-1.40)$ & $1.05(0.82-1.34)$ \\
\hline Surgery plus radiation & $1.40(1.10-1.80)^{\mathrm{c}}$ & $1.26(1.01-1.57)^{\mathrm{b}}$ & $1.13(0.88-1.44)$ & $1.08(0.86-1.36)$ \\
\hline Chemotherapy only & $3.15(1.85-5.36)^{d}$ & $2.51(1.49-4.24)^{d}$ & $2.23(1.29-3.83)^{c}$ & $2.04(1.19-3.49)^{\mathrm{c}}$ \\
\hline Other & $1.70(1.29-2.23)^{\mathrm{d}}$ & $1.85(1.44-2.37)^{\mathrm{d}}$ & $1.52(1.14-2.01)^{c}$ & $1.76(1.36-2.28)^{\mathrm{d}}$ \\
\hline
\end{tabular}

Table 3. Comparison of treatment received by patients in the larynx subgroup analysis

\begin{tabular}{|c|c|c|c|}
\hline Treatment & $\begin{array}{l}\text { Younger } \\
\text { group, } \boldsymbol{n}(\%)\end{array}$ & $\begin{array}{l}\text { Older group, } \\
n(\%)\end{array}$ & $p$ value \\
\hline \multicolumn{4}{|l|}{ Early stage (I and II) } \\
\hline Unimodality therapy & $80(57.1)$ & $25(52.1)$ & .7593 \\
\hline Multimodality therapy & 39 (27.9) & $14(29.2)$ & \\
\hline \multicolumn{4}{|l|}{ Late stage (III and IV) } \\
\hline Unimodality therapy & $67(27.3)$ & $10(23.3)$ & .1886 \\
\hline Multimodality therapy & $163(66.5)$ & $27(62.8)$ & \\
\hline
\end{tabular}

(surgery plus radiation or chemotherapy plus radiation with or without surgery) with the expectation that most patients with early stage disease (stage I or II) could be managed with unimodality therapy, whereas most with later stage disease (stage III or IV) should receive multimodality therapy. Because of concerns about interaction between therapy and site (which vary between younger and older patients), we limited the analysis to patients with cancer of the larynx for tumor homogeneity, common cause (smoking) among both older and younger patients, and large size of the treatment category. There was no difference in the rates of single- and multimodality therapy as a function of age and stage (Table 3).

We then evaluated survival outcomes as a function of age and treatment intensity stratified by early versus late stage for the entire data set. Among early stage patients, older patients had worse OS and PFS (Fig. 1). For early stage patients within both age groups, patients on multimodality therapy did slightly worse, although this was not statistically significant. This is consistent with the possibility that the patients treated with multimodality therapy had higher risk disease within the stage 

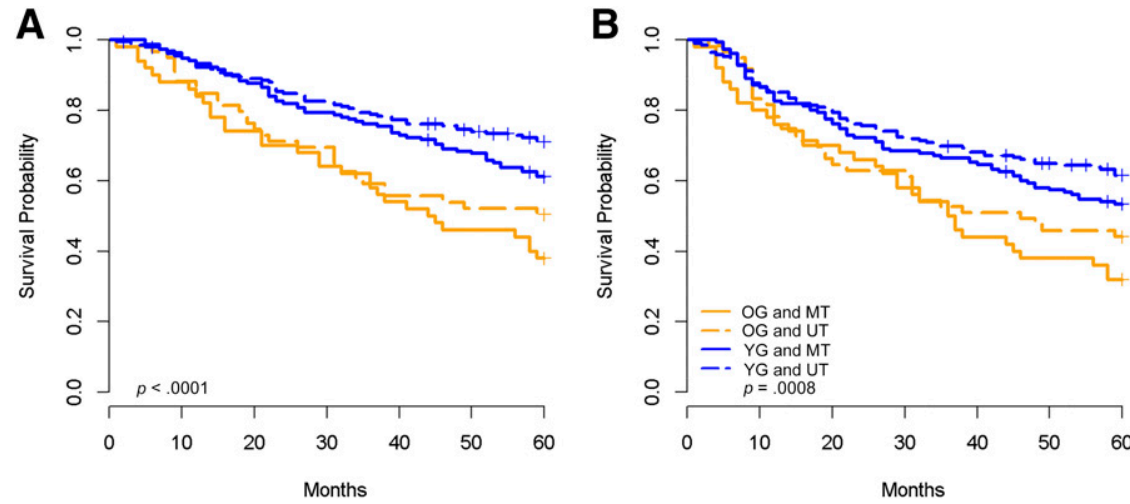

Figure 1. Kaplan-Meier survival plots for all patients with early stage disease (stages I and II) by age group (younger vs. older) and therapy (unimodality versus multimodality). (A): Overall survival. (B): Progression-free survival.

Abbreviations: MT, multimodality therapy; OG, older group; UT, unimodality therapy; YG, younger group.
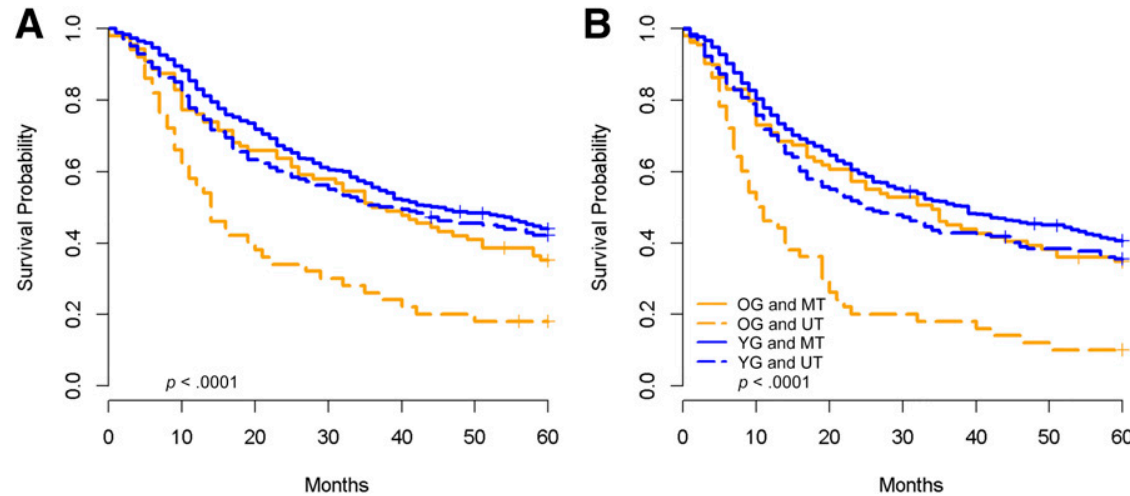

Figure 2. Kaplan-Meier survival plots for all patients with late-stage disease (stages III and IV) by age group (younger vs. older) and therapy (unimodality versus multimodality). (A): Overall survival. (B): Progression-free survival.

Abbreviations: MT, multimodality therapy; OG, older group; UT, unimodality therapy; YG, younger group.

grouping. Although incomplete data limited the use of relapsefree survival as a primary outcome, investigation of relapse in early stage patients showed that older and younger patients relapsed at the same rate, suggesting the difference in OS and PFS was primarily due to noncancer competing causes of mortality.

When considering patients at advanced stages, a striking difference was detected in outcomes by unimodality versus multimodality therapy. Older patients treated with multimodality therapy demonstrated outcomes essentially identical to those of younger patients (Fig. 2). However, older patients treated with unimodality therapy had dismal outcomes overall compared with all other patients (HR for PFS: 1.5; $95 \% \mathrm{Cl}: 1.19-1.89)$. Each of the major anatomic subsites were evaluated independently with entirely consistent results (data not shown). Five-year survival for older patients with advanced stage cancers who received multimodality therapy was slightly lower than for younger patients (33.2\% vs. $44.0 \%$, $p=.0522)$, although the difference was not statistically significant.

In a final analysis, we questioned whether older patients treated with unimodality therapy outperformed patients who received no curative therapy at all. Among older patients with late-stage disease, the HR for death within 5 years for those receiving no therapy or palliative care only compared with those receiving unimodality therapy was 1.69 (95\% Cl: $1.17-2.45 ; p=.0051)$, supporting a survival advantage with unimodality therapy over no therapy.

\section{Selective Chart Review: Older Patients With Advanced Larynx Cancer Treated With Unimodality Therapy}

We identified 24 older patients with advanced larynx cancer who were treated with unimodality therapy. We noted that the majority had multiple comorbidities including cardiac arrhythmias, severe coronary artery disease, previous myocardial infarction, diabetes mellitus, depression, hypertension, chronic renal failure, peripheral vascular disease, dementia, morbid obesity, and psychosis. Furthermore, the majority (75\%) received an initial recommendation for multimodality therapy. Ultimately, $63 \%$ were treated with surgery alone and $37 \%$ received radiation alone. Among these patients, 50\% declined secondary therapy and $17 \%$ died within the first 5 months after diagnosis.

\section{DisCUSSION}

In this study we sought to determine the impact of advanced age on treatment and oncologic outcomes in patients with head and neck cancer. We noted a significant association between advanced age at presentation and survival: patients aged $\geq 70$ years were nearly $50 \%$ more likely to die and $45 \%$ 
more likely to recur within 5 years of diagnosis compared with their younger counterparts. However, we also demonstrated that older patients receiving stage-appropriate treatment for early and late stage cancer had oncologic outcomes equivalent to those of their younger counterparts. These findings suggest that advanced age alone should not preclude patients from receiving stage-appropriate therapy. Given the paucity of clinical trials assessing the impact of advanced age on head and neck cancer outcomes, our findings provide valuable insight for patients and clinicians about the appropriate treatment of elderly patients with head and neck cancer.

The results from our study support the use of stageappropriate therapy for elderly head and neck cancer patients with both early and advanced-stage disease. Although older patients with early stage head and neck cancer demonstrated significantly worse overall survival compared with younger patients, no significant difference in rates of cancer recurrence was noted between older and younger patients. This suggests that the elevated risk of death in the older cohort was attributable in large part to competing causes of mortality. We conclude that most elderly patients with early stage disease should be treated in a stage-appropriate manner and should experience similarly favorable oncologic outcomes when compared with younger patients.

Among patients with late-stage disease, we observed that older patients treated with stage-appropriate multimodality therapy had outcomes comparable to those of younger patients of similar stage. Competing causes of death likely represented a smaller overall contribution to adverse outcomes in this group because cancer is the primary cause of death in patients with late-stage head and neck cancer. These findings are consistent with a retrospective review of patients aged $>70$ years undergoing concomitant chemoradiation for locally advanced head and neck cancer by Maggiore et al. [9] They demonstrated a 5 -year survival of $32 \%$ and found that $86.5 \%$ of patients were able to complete all treatment cycles [9]. Although multimodality therapy appears to provide a survival advantage in appropriately selected patients aged $>70$ years, our results also demonstrate the benefits of unimodality therapy in cases in which more aggressive treatment cannot be tolerated. Outcomes for late-stage older patients treated with unimodality therapy were statistically superior to those who were not treated or who received palliative care only. These data suggest that patient selection is a more significant predictor of treatment tolerability and oncologic outcomes than age alone and that age alone should not preclude stage-appropriate multimodality therapy for advanced head and neck cancer. These data may be useful to patients and clinicians determining how aggressively to treat patients aged $>70$ years, given the lack of clinical trials focused on this population.

Although oncologic outcomes in the elderly advanced cancer group receiving unimodality therapy were superior to no treatment or palliative treatment groups, such patients had 5-year survival rates of $20 \%$, almost half that of any other group in the study. The reasons for such poor outcomes were examined further in a retrospective chart review of older patients with advanced laryngeal cancer treated with unimodality therapy. Specifically, we sought to determine whether receiving unimodality treatment was a function of treatment bias, patient preference, or inability to tolerate therapy. We noted that the majority of patients in this subgroup had significant medical comorbidities. We also demonstrated that the majority of these patients received an initial treatment recommendation for multimodality therapy, suggesting that elderly patients with advanced head and neck cancer are routinely considered for multimodality treatment without bias based on age. Despite this recommendation, a significant percentage of patients declined a second treatment modality. In addition, our review demonstrated that nearly $20 \%$ of patients in this group died in the first 5 months after initiating treatment, underscoring the impact of medical comorbidities and treatment toxicity on oncologic outcomes in this population.

\section{ConCLUSION}

Our study confirmed age as an independent risk factor for survival in patients treated with head and neck cancer. In general, older patients with stage I and II disease did just as well as younger patients in terms of cancer outcomes, with the modestly increased death rates of older patients apparently attributable to competing causes of mortality. In patients with stage III and IV disease, those treated in a stage-appropriate manner with multimodality therapy had overall survival similar to that of younger patients. Late-stage elderly patients treated with unimodality therapy did very poorly. Most of these patients were initially recommended to receive multimodality therapy. Post hoc review of charts offered an initial hypothesis that baseline comorbidities in these patients were high and perhaps could have been used to predict patients who would ultimately receive only one treatment modality. It is unknown whether knowledge that a patient would receive only one modality might alter the initial treatment plan but presumably, in some cases, it would. We believe this study highlights the need for better understanding those factors, including comorbidities and patient preference, that negatively affect execution of planned multimodality therapy in advanced stage head and neck cancer in elderly populations.

\section{ACKNOWLEDGMENTS}

No funding was used in conducting this research. The original data were extracted from the University of North Carolina Cancer Registry.

\section{Author Contributions}

Conception/Design: Virginia A. Moye, Sindhu Chandramouleeswaran, Ni Zhao, Hyman B. Muss, Mark C. Weissler, David N. Hayes

Collection and/or assembly of data: Virginia A. Moye, Sindhu Chandramouleeswaran, David N. Hayes, Jose P. Zevallos

Data analysis and interpretation: Virginia A. Moye, Sindhu Chandramouleeswaran, Ni Zhao, David N. Hayes, Jose P. Zevallos

Manuscript writing: Virginia A. Moye, Sindhu Chandramouleeswaran, Ni Zhao, David N. Hayes, Jose P. Zevallos

Final approval of manuscript: Virginia A. Moye, Sindhu Chandramouleeswaran, Ni Zhao, Hyman B. Muss, Mark C. Weissler, David N. Hayes, Jose P. Zevallos

Disclosures

The authors indicated no financial relationships. 


\section{REFERENCES}

1. Parkin DM, Bray F, Ferlay J et al. Global cance statistics, 2002. CA Cancer J Clin 2005;55:74-108.

2. Bernardi D, Barzan L, Franchin G et al. Treatment of head and neck cancer in elderly patients: State of the art and guidelines. Crit Rev Oncol Hematol 2005; 53:71-80.

3. Bhattacharyya N. A matched survival analysis for squamous cell carcinoma of the head and neck in the elderly. Laryngoscope 2003;113:368-372.

4. Clayman GL, Eicher SA, Sicard MW et al. Surgical outcomes in head and neck cancer patients 80 years of age and older. Head Neck 1998;20:216-223.

5. Horiot JC. Radiation therapy and the geriatric oncology patient. J Clin Oncol 2007;25:1930-1935.

6. Italiano A, Ortholan C, Dassonville $\mathrm{O}$ et al. Head and neck squamous cell carcinoma in patients aged $>$ or $=80$ years: Patterns of care and survival. Cancer 2008;113:3160-3168.

7. Olmi P, Ausili-Cefaro G, Loreggian L. Radiation therapy in the elderly with head and neck cancer. Rays 1997;22(suppl):77-81.

8. Sarini J, Fournier C, Lefebvre JL et al. Head and neck squamous cell carcinoma in elderly patients: A long-term retrospective review of 273 cases. Arch Otolaryngol Head Neck Surg 2001;127: 1089-1092.

9. Maggiore RJ, Curran EK, Witt ME et al. Surviva and selected outcomes of older adults with locally advanced head/neck cancer treated with chemoradiation therapy. J Geriatr Oncol 2013;4:327333.

10. Mell LK, Dignam JJ, Salama JK et al. Predictors of competing mortality in advanced head and neck cancer. J Clin Oncol 2010;28:15-20.

11. Ildstad ST, Tollerud DJ, Bigelow ME et al. A multivariate analysis of determinants of survival for patients with squamous cell carcinoma of the head and neck. Ann Surg 1989;209:237-241.

12. Vaccher $E$, Talamini R, Franchin $G$ et al. Elderly head and neck ( $\mathrm{H}-\mathrm{N})$ cancer patients: A monoinstitutional series. Tumori 2002;88(suppl 1):S63-S66.

13. Olmi P, Ausili-Cefaro G. Radiotherapy in the elderly: A multicentric prospective study on 2060 patients referred to 37 Italian radiation therapy centers. Rays 1997;22(suppl):53-56

14. Sesterhenn AM, Teymoortash A, Folz BJ et al. Head and neck cancer in the elderly: A cohort study in 40 patients. Acta Oncol 2005;44:59-64.

15. Syrigos KN, Karachalios D, Karapanagiotou EM et al. Head and neck cancer in the elderly: An overview on the treatment modalities. Cancer Treat Rev 2009;35:237-245.

16. van der Schroeff MP, Derks W, Hordijk GJ et al. The effect of age on survival and quality of life in elderly head and neck cancer patients: A long-term prospective study. Eur Arch Otorhinolaryngol 2007; 264:415-422.

17. Metges JP, Eschwege F, de Crevoisier R et al. Radiotherapy in head and neck cancer in the elderly: A challenge. Crit Rev Oncol Hematol 2000;34: 195-203.

18. Schofield CP, Sykes AJ, Slevin NJ et al. Radiotherapy for head and neck cancer in elderly patients. Radiother Oncol 2003;69:37-42.

19. Pignon $T$, Horiot JC, Bolla $M$ et al. Age is not a limiting factor for radical radiotherapy in pelvic malignancies. Radiother Oncol 1997;42:107-120.

20. Pignon T, Horiot JC, Van den Bogaert W et al. No age limit for radical radiotherapy in head and neck tumours. Eur J Cancer 1996;32A:2075-2081.

21. Machtay M, Moughan J, Trotti A et al. Factors associated with severe late toxicity after concurrent chemoradiation for locally advanced head and neck cancer: An RTOG analysis. J Clin Oncol 2008;26: 3582-3589.

22. Argiris A, Li Y, Murphy BA et al. Outcome of elderly patients with recurrent or metastatic head and neck cancer treated with cisplatin-based chemotherapy. J Clin Oncol 2004;22:262-268.

23. Lewis $\mathrm{JH}$, Kilgore $\mathrm{ML}$, Goldman DP et al. Participation of patients 65 years of age or older in cancer clinical trials. J Clin Oncol 2003;21: 1383-1389.

24. Murthy VH, Krumholz HM, Gross CP. Participation in cancer clinical trials: Race-, sex-, and agebased disparities. JAMA 2004;291:2720-2726.

25. Muss HB. Cancer in the elderly: A societal perspective from the United States. Clin Oncol (R Coll Radiol) 2009;21:92-98.

26. Talarico L, Chen G, Pazdur R. Enrollment of elderly patients in clinical trials for cancer drug registration: A 7-year experience by the US Food and Drug Administration. J Clin Oncol 2004;22: 4626-4631.

27. Scher KS, Hurria A. Under-representation of older adults in cancer registration trials: Known problem, little progress. J Clin Oncol 2012;30: 2036-2038.

28. Hashibe M, Brennan P, Chuang SC et al. Interaction between tobacco and alcohol use and the risk of head and neck cancer: Pooled analysis in the International Head and Neck Cancer Epidemiology Consortium. Cancer Epidemiol Biomarkers Prev 2009;18:541-550

29. Hashibe M, Brennan $P$, Benhamou $S$ et al. Alcohol drinking in never users of tobacco, cigarette smoking in never drinkers, and the risk of head and neck cancer: Pooled analysis in the Internationa Head and Neck Cancer Epidemiology Consortium. J Natl Cancer Inst 2007;99:777-789. 